Esta revista forma parte del acervo de la Biblioteca Jurídica Virtual del Instituto de Investigaciones Jurídicas de la UNAM

\title{
La responsabilidad internacional de los grupos armados: ¿responsabilidad individual o colectiva?
}

\author{
International Responsibility of Armed Groups: \\ Individual or Collective Responsibility?
}

\section{La responsabilité internationale des groupes armés: responsabilité individuelle ou collective?}

\section{Laura Íñigo Álvarez*}

\begin{abstract}
SUMARIO: I. Introducción. II. La responsabilidad del Estado y de los grupos armados en el trabajo de la Comisión de Derecho Internacional. III. La responsabilidad penal internacional de los grupos armados. IV. Los mecanismos de rendición de cuentas y reparaciones aplicados a los grupos armados. V. ¿Hacia un nuevo modelo de responsabilidad internacional para los grupos armados? Propuestas y desafíos. VI. Conclusiones. VII. Bibliografía.
\end{abstract}

* Cándidata al doctorado en derecho internacional público, doctorado conjunto entre la Universidad de Sevilla (España) y la Universidad de Utrecht (Países Bajos); máster en derecho público y licenciada en derecho por la Universidad de Sevilla.

La presente contribución ha recibido financiación de las ayudas a la investigación para aspirantes predoctorales de la Fundación del Banco Sabadell 2016 (España).

Artículo recibido el 4 de mayo de 2017 Aprobado para publicación el 25 de septiembre de 2017 
RESUMEN: Los grupos armados tienen un papel predominante en las violaciones al derecho internacional humanitario (DIH), así como a los derechos humanos, cometidas en situaciones de conflicto durante las últimas décadas. Aunque existe un consenso en torno a las obligaciones del DIH aplicables a los grupos armados en los conflictos armados no internacionales, no existe una regulación de las consecuencias legales derivadas de la violación de las mismas. Este artículo analiza cuáles han sido las respuestas que ha dado el derecho internacional a la cuestión de la responsabilidad internacional de los grupos armados, desde el punto de vista tanto de sus miembros individuales como de los considerados colectividades. El estudio culmina con una reflexión sobre un nuevo modelo de responsabilidad internacional aplicado a los grupos armados en sí considerados mismos.

Palabras clave: grupos armados, responsabilidad internacional, derecho internacional humanitario (DHI), derecho penal internacional (DPI), Comisión de Derecho Internacional (CDI), derechos humanos, atribución, reparaciones.

ABSTRACT: Armed groups have a predominant role in the violations of international humanitarian law (IHL) and human rights committed in conflict settings during the last decades. Although there is a consensus on the IHL obligations applicable to armed groups during non-international armed conflicts, there is no regulation of the legal consequences of their violation. This article analyses the answers given by the international law to the issue of the international responsibility of the armed groups, both in terms of individual members as well as collectivities. The study will conclude with a reflection on a new model of international responsibility applied to armed groups themselves.

Key words: armed groups, international responsibility, International Humanitarian Law (IHL), International Criminal Law (ICL), International Law Commission (ILC), human rights, attribution, reparations.

RESUMÉ: Les groupes armés ont un rôle prépondérant dans les violations du droit international humanitaire (DIH) et les violations des droits de l'homme dans les situations de conflit de ces dernières décennies. Bien qu'il y ait un consensus sur les obligations du droit international humanitaire applicables aux groupes armés pendant les conflits armés non internationaux, il n'y a pas de réglementation entourant les conséquences juridiques de la violation de celle-ci. Cet article examine quelles sont les réponses données par le droit international à la question de la responsabilité internationale des groupes armés, tant du point de vue de la responsabilité individuelle de ses membres que de leur responsabilité collective. L'étude conclut par une réflexion sur un nouveau modèle de responsabilité internationale appliquée aux groupes armés. Mots-clés: groupes armés, responsabilité internationale, droit international humanitaire (DIH), droit pénal international (ICL), Commission du Droit International (CDI), droits de l'homme, attribution, réparations. 
Esta revista forma parte del acervo de la Biblioteca Jurídica Virtual del Instituto de Investigaciones Jurídicas de la UNAM

\section{INTRODUCCIÓN}

Los conflictos armados de las últimas décadas se han caracterizado por una creciente participación de grupos armados no estatales. Su participación ha traído consigo un aumento de las violaciones al derecho internacional humanitario, así como a los derechos humanos. Así lo han puesto de manifiesto los informes del secretario general de Naciones en materia de protección de civiles, al igual que los informes anuales de Amnistía Internacional y de Human Rights Watch. ${ }^{1}$ En particular, los grupos armados han sido especialmente letales en Afganistán, Irak, Siria, República Centroafricana, República Democrática del Congo, Malí y Nigeria. ${ }^{2}$ El daño que los grupos armados provocan ha suscitado la necesidad de establecer un marco legal internacional efectivo, capaz de dar respuesta a dichas acciones.

En este contexto, cabe resaltar que existe un consenso en relación con las obligaciones que los grupos armados ostentan en los conflictos armados no internacionales, ${ }^{3}$ obligaciones que provienen del artículo 3o. común a los Convenios de Ginebra, al Protocolo Adicional II y al derecho internacional humanitario consuetudinario. ${ }^{4}$ Además, hay una creciente tendencia que reconoce que los grupos armados que ejercen control sobre el territorio y ejercen funciones similares a las estatales están sujetos a una escala

1 Informe presentado por el secretario general al Consejo de Seguridad sobre la protección de los civiles en los conflictos armados, 13 de mayo de 2016, S/2016/447; Informe 2016/2017 Amnistía Internacional. La situación de los Derechos Humanos en el Mundo, Londres 2017; Human Rights Watch, World Report 2017, USA 2017.

2 Informe presentado por el secretario general al Consejo de Seguridad sobre la protección de los civiles en los conflictos armados, 18 de junio de 2015, S/2015/453, pp. 3-10.

3 Existe un conflicto armado cuando "se recurre a la fuerza entre Estados o hay una situación de violencia armada prolongada entre autoridades gubernamentales y grupos armados organizados o entre estos grupos dentro de un Estado". Fiscal v. Tadic a/k/a "DULE”, TPIY, Caso núm. IT-94-1-T, Opinión y sentencia del 7 de mayo de 1997, párr. 628. Véase también Salmón, E., Introducción al derecho internacional humanitario, Comité Internacional de la Cruz Roja, 2012, pp. 29 y 30.

4 Véase Clapham, A., "Obligaciones dimanantes de los derechos humanos para los actores no estatales en situaciones de conflicto”, International Review of the Red Cross núm. 863, 2006, p. 3. 
Esta revista forma parte del acervo de la Biblioteca Jurídica Virtual del Instituto de Investigaciones Jurídicas de la UNAM

gradual de obligaciones en materia de derechos humanos. ${ }^{5}$ Las obligaciones internacionales de grupos armados, tanto a nivel del DIH como de derechos humanos, se encuentran también en los acuerdos de paz y cese de hostilidades. ${ }^{6}$

Sin embargo, desde la publicación de Zegveld en 2002 acerca de la responsabilidad de los grupos armados de oposición en derecho internacional, ${ }^{7}$ se ha prestado poca atención a la cuestión de la responsabilidad de los grupos armados considerados en sí mismos. En este sentido, la doctrina ha señalado que no está claro que la violación de normas primarias del derecho internacional, en particular del DIH, den lugar a consecuencias legales para los grupos armados considerados como colectividades, ni qué consecuencias podrían implicar. ${ }^{8} \mathrm{~A}$ este respecto, el estudio del Comité International de la Cruz Roja (CICR) sobre derecho internacional humanitario consuetudinario ha indicado que "puede afirmarse que [los grupos armados de oposición] incurren en responsabilidad por los actos cometidos por los miembros de esos grupos", admitiendo al mismo tiempo que "las consecuencias de esa responsabilidad no están claras". ${ }^{9}$

Esto apunta a la existencia de una laguna legal en torno a la responsabilidad internacional de los grupos armados considerados como colectividad. Sin embargo, debe resaltarse que la cuestión de la responsabilidad representa un aspecto central del derecho internacional. ${ }^{10}$ De acuerdo con Pellet, "la res-

5 Consejo de Derechos Humanos, Informe de la Comisión Internacional de Investigación para investigar todas las presuntas violaciones del derecho internacional de los derechos humanos en la Jamahiriya Árabe Libia, 1 junio 2011, A/HRC/17/44, p. 33, párr. 72. Véase Murray, D., Human Rights Obligations of Non-State Armed Groups, London, Hart Publishing, 2016.

6 Véase Bell, C., Peace Agreements and Human Rights, Oxford, Oxford University Press, 2000 .

7 Zegveld, L., Accountability of Armed Opposition Groups in International Law, Cambridge University Press, 2002.

8 Bílková, V., "Establishing Direct Responsibility of Armed Opposition Groups for Violations of International Humanitarian Law?”, en Gal-Or, N. et al., Responsibilities of the NonState Actor in Armed Conflict and the Market Place: Theoretical Considerations and Empirical Findings, Leiden-Boston, Brill Nijhoff, 2015, p. 263.

9 Henckaerts, J. M., y Doswald-Beck, L., Derecho internacional humanitario consuetudinario, Buenos Aires, Comité Internacional de la Cruz Roja, vol. I, norma 149, 2007, p. 605.

10 Reuter, P., Le développement de l'ordre juridique international. Écrits de droit international, París, Economica, 1995, p. 574. 
Esta revista forma parte del acervo de la Biblioteca Jurídica Virtual del Instituto de Investigaciones Jurídicas de la UNAM

ponsabilidad es el corolario necesario del derecho", ${ }^{11}$ lo que significa que no hay derecho sin responsabilidad. En la misma línea, Anziolotti afirma que la existencia de un orden internacional da lugar a que aquellos que están sujetos a obligaciones deben ser igualmente responsables en caso de no cumplir con las mismas. ${ }^{12}$ Igualmente, el secretario general de la ONU ha aludido a la necesidad de desarrollar "nuevas medidas para promover la responsabilidad de los grupos armados y de los actores no estatales" en los conflictos armados. ${ }^{13}$

Teniendo en cuenta estas premisas, el presente artículo pretende analizar cuáles han sido las respuestas que ha dado el derecho internacional a la cuestión de la responsabilidad de los grupos armados. En este sentido, aunque la respuesta primordial ha sido establecer la responsabilidad penal individual de sus líderes y miembros, existen otros mecanismos que indirectamente reconocen la responsabilidad colectiva del grupo de modo similar a la responsabilidad del Estado por hechos internacionalmente ilícitos. De este modo, se propone revisar los aspectos colectivos en materia de responsabilidad de los grupos armados, los cuales podrían aportar soluciones más efectivas a las violaciones cometidas por los mismos, en particular, en el ámbito de las reparaciones.

El artículo analizará dichos aspectos en los siguientes apartados. En primer lugar, se examina el proceso de codificación de los artículos sobre la responsabilidad internacional del Estado y su relación con la responsabilidad de los grupos insurgentes. A continuación, se analiza la responsabilidad penal individual de sus miembros, así como los modos de participación. Finalmente, se recogen los mecanismos de rendición de cuentas y reparaciones en relación con la actuación de los grupos armados. El estudio culmina con una reflexión sobre un nuevo modelo de responsabilidad internacional, aplicado a los grupos armados considerados en sí mismos, así como sus ventajas y desafíos.

A los efectos de este artículo el término "responsabilidad internacional” alude a las consecuencias legales que se derivan de la violación de una

11 En el original en inglés "responsibility is the necessary corollary of law". Véase Pellet, A., "The Definition of Responsibility in International Law", en Crawford, J. et al., The Law of International Responsibility. Oxford Commentaries on International Law, Oxford, Oxford University Press, 2010, p. 4.

12 Anzilotti, D., Cours de droit international, París, Panthéon-Assas/LGDJ, 1999, p. 467.

13 Informe presentado por el Secretario General al Consejo de Seguridad sobre la protección de los civiles en los conflictos armados, 28 de mayo de 2004, S/2004/431, párr. 16. 
Esta revista forma parte del acervo de la Biblioteca Jurídica Virtual del Instituto de Investigaciones Jurídicas de la UNAM

obligación internacional. De acuerdo con lo establecido por Roberto Ago, "una cosa es definir una norma y el contenido de la obligación por ella impuesta y otra muy distinta determinar si se ha infringido esa obligación y cuáles deben ser las consecuencias de tal infracción”. ${ }^{14}$ Por ello, en este caso no nos centraremos en las obligaciones (normas primarias) sino en la responsabilidad en sentido estricto (normas secundarias). ${ }^{15}$ Por su parte, los términos "grupos armados" o "grupos insurgentes" se refieren a aquellas agrupaciones que luchan en contra del gobierno u otros grupos armados y que operan en el contexto de los conflictos armados no internacionales, esto es, que han alcanzado al menos el umbral del artículo 3o. común de los Convenios de Ginebra de 1949. Otras situaciones de posconflicto también serán analizadas.

\section{LA RESPONSABILIDAD DEL ESTADO Y DE LOS GRUPOS ARMADOS EN EL TRABAJO DE LA COMISIÓN DE DERECHO INTERNACIONAL}

Tradicionalmente, la responsabilidad de los grupos armados se ha reconducido a los Estados o a los individuos, ya sea a través de la responsabilidad de los Estados por hechos internacionalmente ilícitos o de la responsabilidad penal individual, respectivamente. ${ }^{16}$ Esto se debe a que la subjetividad internacional de los grupos armados ha sido una cuestión sometida a un intenso debate. Por ello, sus acciones debían buscar apoyo en otros sujetos de derecho. En este apartado, trataremos el primero de los aspectos señalados.

En principio, las acciones de los grupos armados pueden atribuirse al Estado de acuerdo con tres preceptos del Proyecto de artículos sobre responsabilidad del Estado por hechos internacionalmente ilícitos (en adelante,

14 Anuario de la Comisión de Derecho Internacional, 1970, vol. II, A/CN.4/233, p. 331, apartado c) del párrafo 66.

15 Sobre las obligaciones de derecho internacional aplicables a los grupos armados, véase Ínigo Álvarez, L., "Los grupos armados ante el derecho internacional contemporáneo: obligaciones y responsabilidad”, Revista Electrónica de Estudios Internacionales, núm. 31, 2016.

16 International Law Association, Third Report on the Obligations and Responsibility of Non-State Actors in International Law, Committee on Non-State Actors, Washington Conference 2014, p. 8. 
Esta revista forma parte del acervo de la Biblioteca Jurídica Virtual del Instituto de Investigaciones Jurídicas de la UNAM

PRIE) elaborados por la Comisión de Derecho Internacional (CDI), ${ }^{17}$ que serían los artículos 8o., 9o. y 10. El artículo 8o. se refiere a aquellos grupos que actúan bajo la dirección o control efectivo del Estado. Por su parte, el artículo 9o. hace referencia a aquellos que ejercen "de hecho atribuciones del poder público en ausencia o en defecto de las autoridades oficiales". Sin embargo, en ambos casos se trataría de grupos armados que actúan, en cierto modo, como instrumentos del Estado. Por lo tanto, estos artículos no bastarían para atribuir la conducta de aquellos grupos armados que luchan en contra del Estado. ${ }^{18}$

Una cuestión distinta es la obligación positiva de los Estados de prevenir o castigar las acciones de individuos o grupos que vulneren el derecho internacional, principalmente, el DIH. En particular, el artículo 1o. de los Convenios de Ginebra establece la obligación del Estado de "respetar y hacer respetar el presente Convenio en todas las circunstancias". Esto significa que los Estados deben proteger a las personas frente a violaciones cometidas no sólo por el Estado, sino también por entidades no estatales; es decir, no sólo respetar, sino hacer respetar. ${ }^{19}$ No obstante, en dicho caso se atribuye al Estado su fracaso a la hora de prevenir violaciones y su falta de diligencia debida, pero no se le atribuyen los actos de dichos individuos o grupos en sí mismos. ${ }^{20}$

En segundo lugar, se encuentran aquellos grupos que posteriormente se convierten en el nuevo gobierno o forman un nuevo Estado de acuerdo con el artículo 10. ${ }^{21}$ Esta regla tiene su fundamento en el principio de continuidad entre dicho movimiento y el eventual Estado ya que, según Roberto Ago, se trataría de un embrión de un Estado que pasa a convertirse en un Estado propiamente dicho, sin interrupción de su subjetividad inter-

17 Proyecto de artículos de la Comisión de Derecho Internacional sobre la responsabilidad internacional del Estado por hechos internacionalmente ilícitos, Asamblea General de las Naciones Unidas Res. A/RES/56/83, 9 de agosto de 2001.

18 International Law Association, op. cit., p. 8.

19 Ryngaert, C. y Van de Meulebroucke, A., "Enhancing and Enforcing Compliance with International Humanitarian Law by Non-State Armed Groups: an Inquiry into some Mechanisms”, Journal of Conflict \& Security Law, vol. 16, núm. 3, 2012, pp. 462 y 463.

20 Bílková, V., op. cit., p. 271. Véase también Ryngaert, C. y Van de Meulebrouckez, A., op. cit., p. 463.

21 Artículo 10, Proyecto de artículos de la Comisión de Derecho Internacional sobre la responsabilidad internacional del Estado por hechos internacionalmente ilícitos. 
Esta revista forma parte del acervo de la Biblioteca Jurídica Virtual del Instituto de Investigaciones Jurídicas de la UNAM

nacional. ${ }^{22}$ Sin embargo, el precepto no indica exactamente a qué grupos se refiere ni cuándo se considera que el movimiento ha pasado a convertirse en un nuevo Estado. ${ }^{23}$

Por tanto, el PRIE sólo recoge los actos de aquellos grupos que triunfan en su lucha contra el Estado para convertirse en el nuevo gobierno o en un nuevo Estado. La cuestión que se plantea, entonces, es qué ocurre con aquellos grupos armados que no derrotan al Estado pero que permanecen activos durante décadas. En este caso existe una norma negativa de atribución recogida anteriormente por los tribunales arbitrales y la práctica de los Estados, según la cual el Estado no podía ser responsable de los daños causados a los extranjeros por un movimiento insurgente que lucha en contra de dicho Estado. ${ }^{24}$

Dicha norma estaba justificada por la imposibilidad de atribuir al Estado la conducta de una entidad que es estructural y funcionalmente independiente del mismo. ${ }^{25}$ Sin embargo, los intereses de las víctimas de dichas violaciones quedaban en suspenso.

Ante esta circunstancia el PRIE ha dejado la puerta abierta a una posible responsabilidad del grupo armado en su conjunto explicando en su comentario que "otra posibilidad es que el grupo insurgente pueda ser considerado responsable por sí mismo de sus propios actos de acuerdo con el derecho internacional, por ejemplo, por una violación del derecho internacional humanitario cometida por sus fuerzas". ${ }^{26}$ Esta idea proviene de los informes del relator especial, Roberto Ago, y de la versión previa del PRIE en su primera lectura de 1996. En el Cuarto Informe sobre responsabilidad del Estado, Ago había declarado que un movimiento insurreccional era un "sujeto de derecho internacional independiente... perfectamente capaz

22 Ago, R., Forth Report on State Responsibility, ILC Yearbook, vol. II, A/CN.4/264 and Add.1, 1972, p. 131, párr. 159.

23 Verhoen, S. I., "International Responsibility of Armed Opposition Groups. Lessons from State Responsibility for Actions of Armed Opposition Groups” en Gal-Or, N. et al., op. cit., pp. 288-294.

24 Cahin, G., "Attribution of Conduct to the State: Insurrectional Movements", en Crawford, J. et al., The law of international..., cit., pp. 252 y 253.

25 Ibidem, p. 253.

26 Artículo 10, comentario párr. 16. Proyecto de artículos de la Comisión de Derecho Internacional sobre la responsabilidad internacional del Estado por hechos internacionalmente ilícitos. 
Esta revista forma parte del acervo de la Biblioteca Jurídica Virtual del Instituto de Investigaciones Jurídicas de la UNAM

de cometer hechos internacionalmente ilícitos". ${ }^{27} \mathrm{Y}$ añadía que "pese a las dificultades, los Estados han presentado a veces reclamaciones contra un movimiento insurreccional por lesiones causadas a éstos o a sus nacionales por órganos de dicho movimiento". ${ }^{28}$

Asimismo, la primera versión del PRIE de 1996 recogía la responsabilidad de los grupos rebeldes o insurgentes en dos artículos: el 14 y el 15. El primero de ellos afirmaba que:

1. El comportamiento de un órgano de un movimiento insurreccional que se establece en el territorio de un Estado, o en cualquier otro territorio bajo su administración no se considerará un hecho de ese Estado según el derecho internacional.

2. El apartado 1 se entenderá sin perjuicio de la atribución al Estado de cualquier otra conducta que se relaciona con la del órgano del movimiento insurreccional y que ha de ser considerado como un hecho de ese Estado en virtud de los artículos 5 a 10 .

3. Del mismo modo, el apartado 1 se entiende sin perjuicio de la atribución del comportamiento del órgano del movimiento insurreccional a ese movimiento, en cualquier caso en que tal atribución pueda hacerse según el derecho internacional". ${ }^{29}$

El apartado tercero de este artículo reconocería la existencia de responsabilidad de los movimientos insurreccionales en sí mismos considerados, atribuyendo dicha responsabilidad a través de la actuación de los órganos de tales grupos. Este apartado se había introducido como cláusula de salvaguarda ante la falta de responsabilidad del Estado. pero sin establecer criterios adicionales de atribución.

27 Ago, R., op. cit., p. 129, párr. 153.

28 Ibidem, p. 139, párr. 180.

29 El texto original en inglés es el siguiente: "1. The conduct of an organ of an insurrectional movement which is established in the territory of a State or in any other territory under its administration shall not be considered as an act of that State under international law. 2. Paragraph 1 is without prejudice to the attribution to a State of any other conduct which is related to that of the organ of the insurrectional movement and which is to be considered as an act of that State by virtue of articles 5 to 10 . 3. Similarly, paragraph 1 is without prejudice to the attribution of the conduct of the organ of the insurrectional movement to that movement in any case in which such attribution may be made under international law". Proyecto de artículos sobre la responsabilidad del Estado por hechos internacionalmente ilícitos, Anuario de la Comisión de Derecho Internacional, vol. II, 1996. 
Esta revista forma parte del acervo de la Biblioteca Jurídica Virtual del Instituto de Investigaciones Jurídicas de la UNAM

Sin embargo, la versión final del PRIE de 2001 eliminó dicho artículo al entender, por un lado, que sólo representaba una norma negativa de atribución, y por otro, que no entraba dentro del ámbito de aplicación de la responsabilidad de los Estados. ${ }^{30}$ Por su parte, el artículo 15, que recogía a aquellos grupos que se convertían en el nuevo gobierno o formaban un nuevo Estado tras el conflicto, pasó a convertirse en el actual artículo 10 referido anteriormente. De este modo, el PRIE sólo ha venido a reconocer las consecuencias legales de los actos de los grupos insurgentes que consiguen derrotar al gobierno o Estado en cuestión, pero no de aquellos cuyas aspiraciones no triunfan, aunque permanecen activos durante décadas.

\section{LA RESPONSABILIDAD PENAL INTERNACIONAL}

DE LOS GRUPOS ARMADOS

En contraposición con el anterior trabajo de la CDI, la responsabilidad de los grupos armados se considera, al día de hoy, en términos de responsabilidad penal individual. Esta última es relativamente reciente en el derecho internacional, siendo su primera expresión institucional la de los Juicios de Núremberg, donde se reconoció que los crímenes internacionales se cometen por hombres y no por entidades abstractas. ${ }^{31}$ Actualmente, la justicia penal internacional se ha consolidado a través de los tribunales penales internacionales creados ad hoc (el Tribunal Penal Internacional para la ex Yugoslavia y el Tribunal Penal Internacional para Ruanda) y de la creación de la Corte Penal Internacional (CPI) en 1998, la cual ha supuesto una gran contribución en la lucha contra la impunidad tanto de los Estados como de los miembros de grupos armados. ${ }^{32}$

En relación con el enjuiciamiento de grupos armados, de las diez situaciones que se encuentran actualmente ante la CPI, seis de ellas se re-

30 Crawford, J., First Report on State Responsibility, ILC Yearbook 1998, A/CN.4/490 and Add. 1-7, pp. 53 y 54, párr. 272-277.

31 Nuremberg IMT: Judgment and Sentences (1947) 41 AJIL 172, 221.

32 Véase Pérez-León Acevedo, J. P., "Surgimiento y consolidación de la responsabilidad penal individual por crímenes de guerra cometidos en conflictos armados no internacionales”, Revista Ius et Praxis, año 13, núm. 2, pp. 287-305. 
Esta revista forma parte del acervo de la Biblioteca Jurídica Virtual del Instituto de Investigaciones Jurídicas de la UNAM

fieren a hechos cometidos por líderes y miembros de grupos armados. ${ }^{33}$ Nos referimos a los casos de la República Centroafricana, ${ }^{34}$ Malí, ${ }^{35}$ Sudan, ${ }^{36}$ Uganda, ${ }^{37}$ y la República Democrática del Congo. ${ }^{38}$ El primer juicio de la CPI, celebrado en enero de 2009, se abrió contra Thomas Lubanga Dyilo, ex líder del movimiento rebelde Unión de Patriotas Congoleños (UPC) que fue acusado y condenado por alistar y reclutar a niños menores de 15 años durante los enfrentamientos en la República Democrática del Congo entre septiembre de 2002 y agosto de 2003. ${ }^{39}$

De acuerdo con el artículo 25(1) del Estatuto de la CPI, la responsabilidad penal internacional cubre las acciones de las personas naturales, pero no la de las personas jurídicas y, en principio, se refiere a la responsabilidad individual. El grupo de trabajo encargado de redactar el Estatuto tuvo en mente la idea de incluir a ciertas organizaciones como empresas, partidos políticos o grupos racistas, pero esto quedó descartado, ya que de este modo se evitaba la criminalización de la simple pertenencia a una organiza-

33 Todas las situaciones y casos ante la CPI pueden consultarse en: https: / /www.icc-cpi.int / pages/situations.aspx (fecha de consulta: 30 abril de 2017). Véase además el cuadro de casos sobre grupos armados ante la CPI en Jo, H., Compliant Rebels: Rebel Groups and International Law inWorld Politics, Cambridge, Cambridge University Press, 2015, p. 44.

34 La condena de Jean-Pierre Bemba Gombo del Movimiento de Liberación de Congo (MLC), y desde 2012, la investigación de los hechos cometidos por los grupos Séleka y antibalaka. Véase Fiscal v. Jean-Pierre Bemba Gombo, CPI, Caso núm. ICC-01/05-01/08. Sentencia del 21 de marzo de 2016.

35 La condena de Al Mahdi, rebelde Tuareg perteneciente al grupo Ansar Dine. Véase Fiscal v. Ahmad Al Faqi Al Mahdi, CPI, Caso núm. ICC-01/12-01/15-171. Sentencia del 27 de septiembre de 2016.

36 El juicio contra Abakaer Nourain del Movimiento de Justicia e Igualdad (JEM). Véase Fiscal v. Abdallah Banda Abakaer Nourain, CPI, Caso núm. ICC-02/05-03/09, Confirmación de cargos de 7 de marzo de 2011.

37 El juicio contra Joseph Kony, el líder del Ejército de Resistencia del Señor (LRA), y contra algunos otros de sus miembros, Vincent Otti, Raska Lukwiya, Okot Odhiambo y Dominic Ongwen. Véase Fiscal v. Joseph Kony,Vincent Otti, Raska Lukwiya, Okot Odhiambo and Dominic Ongwen, CPI, Caso núm. ICC-02/04-01/05, Decisión sobre admisibilidad del caso de acuerdo con el art. 19 (1) Estatuto de la CPI, 10 de marzo de 2009.

38 La condena de Thomas Lubanga del UPC y de Germain Katanga del FRPI y los casos contra Bosco Ntaganda del FPLC y Sylvestre Mudacumura del FDLR. Véase Fiscal v. Germain Katanga, CPI, Caso núm. ICC-01/04-01/07. Sentencia del 7 de marzo de 2014. Fiscal v. Bosco Ntaganda, CPI, Caso núm. ICC-01/04-02/06-309. Decisión de 14 de junio de 2014.

39 Fiscal v. Thomas Lubanga Dyilo, CPI, Caso Núm. ICC-01/04-01/06-2901. Sentencia del 14 de julio de 2012. 
Esta revista forma parte del acervo de la Biblioteca Jurídica Virtual del Instituto de Investigaciones Jurídicas de la UNAM

ción. ${ }^{40}$ Sin embargo, aunque a primera vista parece que la responsabilidad penal de los grupos armados sólo se percibe en términos de responsabilidad del individuo, hay varios elementos que apuntan a la necesidad de una acción colectiva a la hora de cometer ciertos crímenes internacionales.

En primer lugar, el artículo 7(2)(a) del Estatuto de la CPI, en relación con los crímenes de lesa humanidad, requiere de la existencia de "la política de un Estado o de una organización de cometer ese ataque o para promover esa política" como un elemento clave para la comisión del mismo. En este sentido, el crimen de lesa humanidad ha sido considerado un crimen de naturaleza colectiva ya que su comisión requería de una serie de instituciones, personal y medios. ${ }^{41}$ De acuerdo con la actual redacción del Estatuto, el crimen de lesa humanidad puede ser cometido no sólo bajo el control y coordinación del Estado sino también bajo el control de otro tipo de organizaciones, entre las cuales pueden encuadrarse los grupos armados. En particular, en el caso Fiscal v. Tadic, el TPIY entendió que el crimen de lesa humanidad había evolucionado para incluir no sólo a los gobiernos legítimos sino también a aquellas entidades que ejercían un control de facto sobre un determinado territorio. ${ }^{42}$

En segundo lugar, el artículo 25(3)(d) del Estatuto de la CPI, en relación con los modos de participación, se refiere a la contribución de un individuo en la comisión de un crimen por parte de un grupo de personas que tengan una finalidad común. En este sentido, la CPI ha establecido a partir del caso Fiscal v. Mbarushimana que la persona que participa en dicho crimen puede ser tanto miembro de dicha organización como ajena a la misma. ${ }^{43}$ En este caso, uno de los requisitos para considerar dicha participación punible es que se trate de un crimen dentro de la jurisdicción de la CPI cometido por un grupo de personas. Por lo tanto, esto indica que el crimen de referencia es cometido por una colectividad.

40 Clapham, A., "Extending International Criminal Law beyond the Individual to Corporations and Armed Opposition Groups", Journal of International Criminal Justice, vol. 6, 2008, p. 919.

${ }^{41}$ Bassiouni, M. C., Crimes against Humanity in International Criminal Law, Martinus NijhoffDordrecht, 1992, pp. 248 y 249.

42 Fiscal v. Tadic a/k/a "DULE”, TPIY, Caso núm. IT-94-1-T, Opinión y sentencia del 7 de mayo de 1997, párr. 654.

43 Fiscal v. Mbarushimana, CPI, Caso núm. ICC-01/04-01/10-465-Red, Decisión sobre confirmación de cargos de 16 de diciembre de 2011, párr. 273. 
Esta revista forma parte del acervo de la Biblioteca Jurídica Virtual del Instituto de Investigaciones Jurídicas de la UNAM

Estos dos ejemplos muestran que la responsabilidad individual a la hora de cometer ciertos crímenes internacionales está ligada a las acciones colectivas de un grupo, ya que sin dicho apoyo el individuo no tendría los medios para cometerlo. En este sentido, Mégret entiende que la responsabilidad penal internacional de los individuos deriva de liderar u obedecer al Estado o a un grupo armado organizado, pero no surge de forma aislada. ${ }^{44}$ Por tanto, si dichas acciones responden a la política coordinada de un grupo, ¿por qué la responsabilidad queda relegada únicamente a varios individuos?

En el caso de la responsabilidad del Estado, ésta ha sido declarada compatible con la responsabilidad individual de sus agentes, ya que, aunque ambas surgen del mismo acto, responden a distintas finalidades. ${ }^{45}$ La responsabilidad penal individual tiene como objetivo luchar contra la impunidad y castigar a los perpetradores de dichas violaciones, mientras que la responsabilidad del Estado responde a la necesidad de restablecer el orden internacional a su status quo y reparar los daños causados. ${ }^{46}$ Así ocurrió con el caso del genocidio en Bosnia donde la condena de agentes individuales de la antigua Yugoslavia, por los hechos cometidos durante el conflicto armado entre 1991 y 1995 ante el TPIY y ante otros tribunales nacionales, no impidió que la Corte Internacional de Justicia (CIJ) determinara la responsabilidad de Serbia en el genocidio. ${ }^{47}$ Asimismo, en el caso Lockerbie se condenó penalmente a Al Megrahi, agente libio, por el atentado aéreo, y al mismo tiempo se solicitó compensación a Libia por parte del Reino Unido

44 Mégret, F., "The Subjects of International Criminal Law”, en Kastner, P. (ed.), International Criminal Law in Context, Taylor and Francis, 2017, p. 9, disponible en: https: / /ssrn.com / abstract $=2934351$ (fecha de consulta: 25 de abril de 2017).

45 Art. 58 PRIE, art. 25(4) Estatuto de Roma de la CPI.Véase Nollkaemper, A., "Concurrence between Individual Responsibility and State Responsibility in International Law", The International and Comparative Law Quarterly, vol. 52, núm. 3, 2003.

46 El preámbulo del Estatuto de Roma de la CPI se refiere a "The States Parties to this Statute... determined to put an end to impunity for the perpetrators of these crimes and thus to contribute to the prevention of such crimes". Por su parte, el PRIE incluye en el contenido de la responsabilidad internacional la obligación de cesar en la comisión de dicha violación, continuar ejerciendo sus obligaciones y reparar el daño causado (artículos 29, 30 y 31). Véase también Bílková, V., op. cit., p. 273.

47 Aplicación de la Convención para la prevención y la sanción del delito de Genocidio, Caso Bosnia y Herzegovina vs. Yugoslavia, CIJ. Sentencia del 26 de febrero de 2007, párr. 403. Véase también Nollkameper, A., op. cit. p. 620. 
Esta revista forma parte del acervo de la Biblioteca Jurídica Virtual del Instituto de Investigaciones Jurídicas de la UNAM

y de Estados Unidos, la cual aceptó su responsabilidad civil al ofrecer 2,700 millones de dólares para indemnizar a los familiares de las víctimas. ${ }^{48}$

Del mismo modo, en el caso de las empresas, se empieza a debatir su responsabilidad civil (tort law) por su complicidad en la comisión de crímenes internacionales, como ha ocurrido en Estados Unidos a través del Alien Tort Statute, el cual permite iniciar acciones civiles por parte de extranjeros por violación del derecho internacional. ${ }^{49}$ Las acciones civiles permiten a las víctimas obtener una compensación por los daños sufridos, mientras que algunos sistemas legales no ofrecen tales mecanismos en los procesos penales. ${ }^{50}$

Por ello, esta posibilidad podría aplicarse mutatis mutandis a las violaciones cometidas por otras entidades como los grupos armados, en la medida en que actúan como colectividades con una jerarquía clara y un control efectivo de sus miembros. Se trataría de compatibilizar la responsabilidad penal de sus miembros con la responsabilidad del grupo en materia de reparaciones. Así lo ha sugerido Drumbl, al indicar que nada impediría que se celebraran juicios penales para los miembros con mayores responsabilidades en la jerarquía del grupo y al mismo tiempo el grupo en su conjunto también fuera sancionado. ${ }^{51}$

\author{
IV. LOS MECANISMOS DE RENDICIÓN DE CUENTAS \\ Y REPARACIONES APLICADOS A LOS GRUPOS ARMADOS
}

Además de la responsabilidad del Estado y la responsabilidad penal del individuo, existen mecanismos de rendición de cuentas en materia de derechos humanos en los que cada vez se pone más énfasis en las acciones llevadas a

48 Abogado de su Majestad v. Al Megrahi, Alto Tribunal de Justicia Escocés en Camp Zeist, Países Bajos, 40 ILM 582, Sentencia del 31 de enero de 2001. Véase "Libya admits Lockerbie blame”, BBC News, 16 de agosto de 2003, disponible en: http: / /news.bbc.co.uk/2/hi/uk_news/ scotland/3155523.stm (fecha de consulta: 23 de abril de 2017).

49 Clapham, A., "Focusing on Armed Non-State Actors" en Clapham, A. y Gaeta, P., The Oxford Handbook of International Law in Armed Conflict, Oxford, Oxford University Press, 2014, pp. 807 y 808.

50 Mongelard, E., “Corporate Civil Liability for Violations of International Humanitarian Law”, International Review of the Red Cross núm. 863, vol. 88, 2006, p. 667.

51 Drumbl, M. A., "Collective Responsibility and Post-Conflict Justice”, en Isaacs, T. y Vernon, R. (eds.), Accountability for CollectiveWrongdoing, Cambridge University Press, 2011, p. 54 . 
Esta revista forma parte del acervo de la Biblioteca Jurídica Virtual del Instituto de Investigaciones Jurídicas de la UNAM

cabo por los grupos armados, y no sólo por los Estados. En este sentido, destacan tres tipos de mecanismos: el sistema de monitoreo de derechos humanos del Consejo de Derechos Humanos (y sus relatores especiales) y del secretario general de Naciones Unidas; las comisiones de la verdad, y las comisiones de investigación de Naciones Unidas.

El Consejo de Derechos Humanos de la ONU tiene como objetivo principal considerar las situaciones de violaciones de los derechos humanos y hacer recomendaciones al respecto. Durante las últimas décadas sus procedimientos se han referido tanto a abusos cometidos por Estados como por grupos armados. En particular, destacan los informes relativos a Malí, Siria y Libia. El informe sobre Malí de la Alta Comisionada de la ONU para los Derechos Humanos de 2013 estableció una lista de violaciones a estos derechos cometidas por los grupos armados. ${ }^{52}$ Por otro lado, en el caso de Siria y Libia, el Consejo de Derechos Humanos ha condenado en varias ocasiones la práctica del secuestro, toma de rehenes, detención en régimen de incomunicación, abusos y asesinatos por parte del Estado Islámico y de otros grupos armados, especialmente durante 2015 y $2016 .{ }^{53}$

Por su parte, el secretario general ha nombrado un representante especial en materia de niños en conflictos armados que, junto con el Consejo de Seguridad, ha puesto en práctica un sistema de seguimiento y supervisión (monitoring and reporting mechanism), así como la elaboración de planes de acción para hacer frente a las graves violaciones cometidas contra los niños por fuerzas tanto gubernamentales como por grupos armados. ${ }^{54}$ De los veintitrés planes de acción firmados hasta el momento, doce de ellos han

52 Entre otras, ejecuciones extrajudiciales y sumarias; tortura y otros tratos crueles, inhumanos o degradantes; detenciones y encarcelamientos arbitrarios; reclutamiento de niños soldados; abusos sexuales; ataques a la propiedad; violaciones de la libertad de expresión y del derecho a la información, del derecho a la educación, derecho a la salud, derechos culturales, y del derecho a la libertad religiosa. Informe de la Alta Comisionada de la ONU para los Derechos Humanos sobre la situación de derechos humanos en Malí, A/HRC/22/33, 7 de enero de 2013.

53 Resolución del Consejo de Derechos Humanos 28/20,A/HRC/28/L.6, 23 de marzo de 2015, disponible en: https: / /documents-dds-ny.un.org/doc/UNDOC/LTD/G15/060/45/PDF/ G1506045.pdf? OpenElement (fecha de consulta: 10 de abril de 2017). Resolución del Consejo de Derechos Humanos 31 /27,A/HRC/31 / L.20,22 de marzo de 2016, disponible en: https: / / docu ments-dds-ny.un.org/doc/UNDOC/LTD/G16/057/35/PDF/G1605735.pdf?OpenElement (fecha de consulta: 10 de abril de 2017).

54 Ryngaert, C. y Van de Meulebrouckez, A., op. cit., pp. 458 y 459. 
Esta revista forma parte del acervo de la Biblioteca Jurídica Virtual del Instituto de Investigaciones Jurídicas de la UNAM

sido firmados por grupos armados no estatales. ${ }^{55}$ Los planes de acción tienen como fin que el grupo armado tome las medidas necesarias para cesar en la comisión de violaciones, especialmente el reclutamiento de niños, y de este modo, ser eliminado de la lista de perpetradores persistentes. ${ }^{56}$

Las comisiones de la verdad son organismos oficiales sin carácter judicial que se encargan de investigar violaciones al DIH y a los derechos humanos cometidas en un período de tiempo y en un territorio concreto con el objeto de elaborar un informe final y formular recomendaciones. ${ }^{57}$ Estas comisiones documentan las actuaciones tanto de Estados como de otros sujetos y entidades no estatales involucrados en tales violaciones. Por ejemplo, la Comisión para el Esclarecimiento Histórico de Guatemala, aunque mayoritariamente se centra en las violaciones cometidas por el Estado, también se refirió a las violaciones de derechos humanos cometidas por los grupos armados insurgentes. ${ }^{58}$

De modo similar, las comisiones de investigación de la ONU sirven para determinar situaciones graves de violaciones al DIH y a los derechos humanos, así como para promover la responsabilidad de las mismas y combatir la impunidad. Las comisiones de investigación tienden a incluir cada vez más en sus mandatos la exigencia de responsabilidad y la identificación de los perpetradores de dichas violaciones. ${ }^{59}$ En particular, Bellal apunta a la utilización de las comisiones de investigación como herramientas útiles para

55 El listado de los planes de acción puede consutarse en: https: / / childrenandarmedconfli ct.un.org/es/nuestro-trabajo/planes-de-accion (fecha de consulta: 15 de abril de 2017). Véase además Márquez Carrasco, C. et al., Survey Study on Human RightsViolations in Conflict Settings, EU FP7 Research Project, Deliverable núm. 10.1, 30 de septiembre de 2014, pp. 152-154, disponible en http://www.fp7-frame.eu/wp-content/uploads/2016/08/08-Deliverable-10.1.pdf (fecha de consulta: 12 de marzo de 2017).

56 Idem.

57 Véase Hayner, P. B., “Comisiones de la verdad: resumen esquemático”, International Review of the Red Cross, núm. 868, 2006, pp. 1-18.

58 Guatemala Memoria del Silencio, Resumen ejecutivo, conclusiones y recomendaciones, UN Doc. A/53/928 Anexo, 27 de abril de 1999, apartados 1699 y 1700, vol. II, pp. 312 y 313.

59 Oficina del Alto Comisionado de las Naciones Unidas para los Derechos Humanos, Comisiones de Investigación y Misiones de Determinación de los Hechos en Derechos Humanos y Derecho Internacional Humanitario, Nueva York, Ginebra, 2015, p. 13, disponible en: http: / /www.ohchr. org/Documents/Publications/CoI_Guidance_and_Practice_sp.pdf (fecha de consulta: 15 de abril de 2017). 
Esta revista forma parte del acervo de la Biblioteca Jurídica Virtual del Instituto de Investigaciones Jurídicas de la UNAM

establecer la responsabilidad de los grupos armados no estatales como un procedimiento preliminar. ${ }^{60}$

El análisis que realizan estos tres mecanismos muestra ciertos puntos en común. En particular, a la hora de determinar las violaciones de derecho internacional cometidas por los grupos armados, estos mecanismos ponen especial atención en detallar las acciones colectivas llevadas a cabo por el grupo. Sin embargo, en el apartado de conclusiones y recomendaciones sólo se refieren a la responsabilidad penal de los individuos. Así lo indica Zegveld al afirmar que los organismos internacionales han dado prioridad a la responsabilidad penal individual en detrimento de la responsabilidad de los grupos. ${ }^{61}$

Esto puede verse reflejado en el informe final de la Comisión de la Verdad y Reconciliación de Sierra Leona, en el cual la Comisión determinó que todos los grupos armados involucrados en el conflicto eran responsables de violaciones de derechos humanos, en especial el RUF (Revolutionary United Front). ${ }^{62}$ Sin embargo, en el apartado sobre metodología, la prioridad de la Comisión es la de establecer la responsabilidad penal de los líderes. ${ }^{63}$ También se manifiesta en la Comisión de Investigación de Siria donde el tercer informe se refiere a la responsabilidad de los grupos armados contrarios al gobierno en un apartado distinto al de la responsabilidad penal individual, mientras que los sucesivos informes sólo hacen referencia a la responsabilidad penal de los individuos. ${ }^{64}$

Por otro lado, las reparaciones llevadas a cabo por ciertos grupos armados representan un reconocimiento indirecto de su responsabilidad internacional. En los últimos años, se ha apreciado una tendencia que destaca la obligación

60 Bellal, A., "Non-State Armed Groups in Transitional Justice Processes Adapting to New Realities in Conflict”, en Duthie, R., y Seils, P. (eds.), Justice Mosaics: How Context Shapes Transitional Justice in Fractured Societies, New York, ICTJ, 2017, p. 4, disponible en: https: / /ssrn. com/abstract $=2939815$ (fecha de consulta: 15 de abril de 2017).

61 Zegveld, L., op. cit. p. 223.

62 Final Report of Sierra Leone's the Truth and Reconciliation Commission, 2004, vol. 2, cap. 2, párrs. 12-38.

63 Ibidem, vol. 1, cap. 5, párr. 66.

64 Consejo de Derechos Humanos de la ONU, Informe de la Comisión de Investigación Internacional Independiente sobre la situación en la Republica Árabe Siria, A/HRC/21/50, 16 de agosto de 2012, p. 21-22, párrs. 131-142. Véase también Bellal, A., "Establishing the Direct Responsibility of Non-State Armed Groups for Violations of International Norms: Issues of Attribution” en Gal-Or, N. et al., op. cit., p. 318. 
Esta revista forma parte del acervo de la Biblioteca Jurídica Virtual del Instituto de Investigaciones Jurídicas de la UNAM

de los grupos armados de reparar los daños causados durante los conflictos armados. Esto puede verse en los Principios y directrices básicos sobre el derecho de las víctimas de violaciones manifiestas de las normas internacionales de derechos humanos y de violaciones graves del derecho internacional humanitario a interponer recursos y obtener reparaciones (Principios básicos en adelante). ${ }^{65}$ De acuerdo con el artículo 15 de dichos Principios, "cuando se determine que una persona física o jurídica u otra entidad está obligada a dar reparación a una víctima, la parte responsable deberá conceder reparación a la víctima o indemnizar al Estado si éste hubiera ya dado reparación a la víctima”. Con lo que se entiende que las reparaciones dejan de ser una obligación exclusiva de los Estados, ya que otras entidades también estarán obligadas en la medida en la que se determine su responsabilidad. ${ }^{66}$

En esta misma línea, la Comisión de Investigación de Darfur indicó que no sólo los Estados tienen la obligación de compensar sino que una obligación similar le corresponde a los grupos rebeldes "por todos los crímenes que hayan cometido, se hayan o no identificado y castigado a los perpetradores". ${ }^{67}$ Del mismo modo, la Comisión de Investigación de Siria ha aludido también a la necesidad de que los grupos armados contrarios al gobierno "otorguen reparación efectiva a las víctimas con arreglo a las normas internacionales". ${ }^{68}$

Además, hay que mencionar los casos de los grupos armados que se han comprometido a proveer reparaciones a las víctimas. En este sentido, el Acuerdo de Paz entre el Gobierno de Colombia y las FARC refuerza "el principio de reconocimiento de responsabilidad por parte de todos quienes participaron de manera directa o indirecta en el conflicto y se vieron involucrados de alguna manera en graves violaciones a los derechos humanos y graves infracciones al Derecho Internacional Humanitario” y por otro lado "el principio de satisfacción de los derechos de las víctimas a

65 Resolución 60/147 aprobada por la Asamblea General el 16 de diciembre de 2005.

66 Véase Moffet, L., "Beyond Attribution: Responsibility of Armed Non-State Actors for Reparations in Northern Ireland, Colombia and Uganda”, en Gal-Or, N. et al., op. cit., pp. 323-346.

67 International Commission of Inquiry on Darfur, Report to the Secretary-General, 25 January 2005, p. 152, párr. 600.

68 Consejo de Derechos Humanos de la ONU, Informe de la Comisión de Investigación Internacional Independiente sobre la situación en la República Árabe Siria, A/HRC/22/59, 5 de febrero de 2013, p. 27, párr. 177(d). 
Esta revista forma parte del acervo de la Biblioteca Jurídica Virtual del Instituto de Investigaciones Jurídicas de la UNAM

la verdad, la justicia, la reparación y la no repetición”. ${ }^{69}$ Anteriormente, la Ley de Justicia y Paz de 2005 incorporaba en su artículo 42 el deber general de los miembros de los grupos armados de reparar a las víctimas de tales violaciones. ${ }^{70}$ En aplicación de dicha ley, la Corte Constitucional de Colombia en el caso Gustavo Gallón y otros entendió que "todos y cada uno de los miembros del grupo armado organizado al margen de la ley... también responderán solidariamente por los daños ocasionados a las víctimas por otros miembros del grupo armado específico al cual pertenecieron". ${ }^{71}$ De esto modo, se reconoce la responsabilidad solidaria de todos los miembros del grupo armado a la hora de otorgar reparaciones. Por otro lado, las partes del conflicto en el norte de Uganda, el gobierno de Uganda y el LRA habían acordado otorgar reparaciones individuales y colectivas a las víctimas de graves crímenes y abusos de derechos humanos en el acuerdo de rendición de cuentas y reconciliación. ${ }^{72}$

Otro de los ejemplos en materia de asunción de responsabilidades por parte de los grupos armados se contempla en el trabajo nombrado Llamamiento de Ginebra (Geneva Call) que realiza la ONG. A través de las llamadas Escrituras de Compromiso los grupos armados se comprometen a respetar determinadas normas del DIH, como la prohibición total de las

69 Acuerdo Final para la Terminación del Conflicto y la Construcción de una Paz Estable y Duradera entre el Gobierno de Colombia y las FARC, 12 de noviembre de 2016, p. 127, disponible en: http: / / app.eltiempo.com/contenido/politica/proceso-de-paz/ARCHIVO / ARCHIVO16749856-0.pdf (fecha de consulta: 20 de abril de 2017). El 4 de abril de 2017 se firmó el decreto para la creación de la Comisión para el Esclarecimiento de la Verdad, la Convivencia y la No Repetición. "Así funcionará la nueva Comisión para el Esclarecimiento de la Verdad”, El Tiempo, 5 de abril de 2017, disponible en: http:/ /www.eltiempo.com/politica/proceso-de-paz/ que-es-la-comision-para-el-esclarecimiento-de-la-verdad-la-convivencia-y-no-repeticion-75166 (fecha de consulta: 25 de abril de 2017).

70 Artículo 42, Ley de Justicia y Paz, Ley 975 de 2005, Diario Oficial 45.980, disponible en: https://www.cejil.org/sites/default/files/ley_975_de_2005_0.pdf (fecha de consulta: 22 de julio de 2017).

71 Corte Constitucional, sentencia C-370 del 18 de mayo de 2006, M. P. Manuel José Cepeda Espinosa, Jaime Córdoba Triviño, Rodrigo Escobar Gil, Marco Gerardo Monroy Cabra, Álvaro Tafur Galvis y Clara Inés Vargas Hernández, párr. 6.2.4.4.13, disponible en: http: / / www.corteconstitucional.gov.co/relatoria/2006/c-370-06.htm (fecha de consulta: 22 de julio de 2017).

72 Acuerdo sobre rendición de cuentas y reconciliación entre el Gobierno de la República de Uganda y el Ejército de Resistencia del Señor (Lord's Resistance Army, LRA), 29 de junio de 2007, Preámbulo y Cláusula 9. Véase también Moffet, L., op. cit., pp. 343-345. 
Esta revista forma parte del acervo de la Biblioteca Jurídica Virtual del Instituto de Investigaciones Jurídicas de la UNAM

minas antipersonal, la protección de niños y la prohibición de violencia sexual en conflictos armados. ${ }^{73}$ La organización realiza un seguimiento y evaluación para comprobar el cumplimiento de las mismas, e incluso pueden llevar a cabo misiones de verificación en el terreno, como en el caso del MILF (Moro Islamic Liberation Front) en Filipinas, en el que el objetivo era investigar si se habían utilizado minas antipersonal y si dicho uso podía atribuirse al citado grupo armado. ${ }^{74}$ En el caso de Colombia, el Llamamiento de Ginebra ha involucrado a líderes y miembros de las FARC y del ELN en las materias citadas. En concreto, el ELN ha llevado a cabo labores de desminado y ha mostrado su voluntad a la hora de eliminar minas en aquellas zonas en beneficio de la población civil. ${ }^{75}$

\title{
V. ¿HACIA UN NUEVO MODELO DE RESPONSABILIDAD INTERNACIONAL PARA LOS GRUPOS ARMADOS? PROPUESTAS Y DESAFÍOS
}

\begin{abstract}
Las secciones anteriores han apuntado a la existencia de un reconocimiento indirecto de la responsabilidad de los grupos armados considerados en sí mismos, ya sea a través de la responsabilidad penal individual, los mecanismos de rendición de cuenta y monitoreo de Naciones Unidas o de la obligación de otorgar reparaciones. Sin embargo, nos encontramos con un marco normativo fragmentado ya que, como indicamos en la introducción, existen normas primarias de DIH aplicables a los grupos armados, pero no normas secundarias.

Ante esta circunstancia, diversos autores han puesto de manifiesto la necesidad de clarificar las normas y los principios aplicables a los grupos armados en relación con su responsabilidad internacional, entendidos como

73 Geneva Call, Escrituras de compromiso en: https://genevacall.org/es/enfoque/escrituracompromiso (fecha de consulta: 22 de julio de 2017).

74 Geneva Call, Report of the 2009 Verification Mission to the Philippines to investigate allegations of anti-personnel landmine use by the Moro Islamic Liberation Front, 2010, disponible en: https: / / genevacall.org/wp-content/uploads/dlm_uploads/2013/12/Report-of-the2009-Verification-Mission-to-the-Philippines-to-Investigate-Allegations-of-Anti-Personnel-LandmineUse-by-the-Moro-Islamic-Liberation-Front.pdf (fecha de consulta: 22 de julio de 2017).

75 Geneva Call, Colombia en: https://genevacall.org/es/country-page/colombia (fecha de consulta: 22 de julio de 2017).
\end{abstract}


Esta revista forma parte del acervo de la Biblioteca Jurídica Virtual del Instituto de Investigaciones Jurídicas de la UNAM

colectividad y no como miembros individuales. ${ }^{76}$ En particular, Sassòli ha indicado que "si bien hoy en día no se discute que los grupos armados son internacionalmente responsables por violaciones del DIH, las normas exactas sobre la atribución, el contenido y la implementación de dicha responsabilidad aún no se han aclarado". ${ }^{77}$ En este sentido, la Comisión de Actores no Estatales de la Asociación de Derecho Internacional ha reconocido que "el mecanismo de responsabilidad directa de los grupos armados de oposición parece ser, en el mejor de los casos, una doctrina in statu nascendi". ${ }^{78}$

Este nuevo modelo de responsabilidad que se propone parece ser uno análogo al de responsabilidad del Estado, con una finalidad reparadora. De hecho, algunos autores han propuesto la aplicación por analogía de algunos de sus preceptos, si bien teniendo en cuenta las particularidades de los grupos armados. ${ }^{79}$ La terminología que se emplea en este sentido es la de "responsabilidad colectiva" (por contraposición a la responsabilidad individual) ${ }^{80} \mathrm{o}$ "responsabilidad directa" (por contraposición a la responsabilidad indirecta a través del Estado o el individuo). ${ }^{81}$ Igualmente, se trata de evitar el término "responsabilidad corporativa" que normalmente se refiere a las empresas. ${ }^{82}$ Sin embargo, el término "responsabilidad colectiva" podría dar lugar a confusión ya que éste proviene de la ética y la filosofía

76 Kleffner, J. K., "The Collective Accountability of Organized Armed Groups for System Crimes”, en Nollkaemper, A. y Wilt, H. V. D., System Criminality in International Law, Cambridge, Cambridge University Press, 2009, pp. 257-268; Bellal, A., op. cit., nota 65, p. 310.

77 El orginal en inglés: "While it is today uncontroversial that armed groups are internationally responsible for violations of IHL, the exact rules on attribution, content and implementation of such responsibility are not yet clarified”. Sassòli, M., "Taking Armed Groups Seriously: Ways to Improve their Compliance with International Humanitarian Law”, Journal of International Humanitarian Legal Studies, vol. 1, núm. 1, 2010, p. 44.

78 International Law Association, op. cit., p. 11.

79 Kleffner, J. K., op. cit., pp. 260-268; Heffes, E., “The Responsibility of armed opposition groups for Violations of International Humanitarian Law: Challenging the State-Centric System of International Law", Journal of International Humanitarian Legal Studies, vol. 4, 2013, pp. 81-107; Ínigo Álvarez, L., "Los grupos armados ante el derecho internacional contemporáneo: Obligaciones y responsabilidad”, Revista Electrónica de Estudios Internacionales, núm. 31, 2016, p. 19.

80 Kleffner, J. K., op. cit., pp. 240-421; Bellal, A., op. cit. nota 61, pp. 2-16.

81 International Law Association, op. cit., p. 11; Bílková, V., op. cit., pp. 265 y 266.

82 Véase Cannon, T., Corporate Responsibility:A Textbook on Business Ethics, Governance, Environment: Roles and Responsibilities, London, Financial Times Management, 1994. 
Esta revista forma parte del acervo de la Biblioteca Jurídica Virtual del Instituto de Investigaciones Jurídicas de la UNAM

del derecho y se refiere a la responsabilidad moral de los miembros de una comunidad o sociedad, ${ }^{83}$ y en ocasiones también se relaciona con castigos colectivos. ${ }^{84}$ Por ello, quizás sería conveniente hablar de responsabilidad del grupo o responsabilidad organizativa de los grupos armados.

A la hora de materializar un posible régimen de responsabilidad de los grupos armados entendidos como colectividades, uno de los aspectos fundamentales a tener en cuenta sería el establecimiento de normas de atribución. Si el grupo tiene una jerarquía clara y un control de sus miembros, sería posible determinar al menos de facto los principales órganos y agentes del mismo, como ya mencionó la primera versión del PRIE en su artículo 14. Por ejemplo, el relator especial en materia de derechos humanos en $\mathrm{Su}$ dán dejó claro que el SPLA (Sudanese People's Liberation Army) ostentaba la responsabilidad de las violaciones y atrocidades cometidas en 1995 por sus comandantes locales, ${ }^{85}$ estableciendo así una norma de atribución. En esta línea, en los comentarios presentados al secretario general de Naciones Unidas en relación con la Declaración sobre las Normas Humanitarias Mínimas, se sugirió insertar un artículo que indicara lo siguiente: "Toda autoridad de jure o de facto es responsable de los actos cometidos por sus agentes, incluidos los actos que afecten negativamente a los derechos humanos fundamentales de cualquier persona en situaciones de emergencia”. Otros autores han aludido al paralelismo con la noción de participación directa en las hostilidades para determinar quiénes son los miembros del grupo y, por tanto, atribuir dicha responsabilidad a la colectividad. ${ }^{86}$ En todo caso, sería necesario un estudio pormenorizado de la estructura organizativa de los grupos armados para poder establecer, en cada caso, los miembros y agentes que pertenecen al grupo.

Además, habría que examinar cuáles serían las consecuencias concretas a las que estarían sometidos los grupos armados y qué procedimientos se

83 Véase May, L. y Hoffman, S. (eds.), Collective Responsibility: Five Decades of Debate in Theoretical and Applied Ethics, Savage, Md. Rowman \& Littlefield, 1991.

84 Darcy, S., Collective Responsibility and Accountability under International Law, Leiden, Transnational Publishers, 2007, p. XXIII y cap. 1.

85 UN General Assembly, Report of the Special Rapporteur on the Situation of Human Rights in the Sudan, 16 de octubre de 1995, A/50/569, párr. 73.

86 Mastorodimos, K., Armed Non-State Actors in International Humanitarian and Human Rights Law. Foundation and Framework of Obligations, and Rules on Accountability, Ashgate Publishing, 2016, p. 123. 
Esta revista forma parte del acervo de la Biblioteca Jurídica Virtual del Instituto de Investigaciones Jurídicas de la UNAM

habilitarían para ello. En principio nada impediría que los grupos armados estuvieran sometidos a criterios similares a los estatales en la medida de lo posible ${ }^{87}$ En este sentido, Sassòli apunta que si existe responsabilidad del grupo armado, la consecuencia lógica es que tengan la obligación de cesar en la comisión de tal violación y otorgar reparaciones de forma similar al Estado. ${ }^{88}$ Moffet se refiere a los casos en que los grupos armados dispongan de recursos económicos, ya que éstos podrían utilizarse para financiar las indemnizaciones de las víctimas, las restituciones en especie o los programas de rehabilitación. ${ }^{89}$ Otros autores aluden a la posibilidad de que los grupos armados provean reparaciones simbólicas o, en palabras del PRIE, satisfacción en forma de reconocimiento de la responsabilidad, disculpa pública u otras formas de compensación no financieras. ${ }^{90}$

En cuanto al valor añadido de este posible régimen de responsabilidad, pueden mencionarse algunas ventajas. En primer lugar, la posibilidad de obtener reparaciones incrementaría si el responsable de las mismas es una colectividad en lugar de un individuo, atendiendo así a los derechos de las víctimas. ${ }^{91}$ Dichas reparaciones podrían ser tanto financieras como de otro tipo, al igual que ocurre con la responsabilidad del Estado en sus variantes de restitución, compensación y satisfacción. En segundo lugar, el establecimiento de una responsabilidad del grupo crearía una cultura de disuasión y cumplimiento, ya que sólo el grupo podría tomar medidas preventivas. ${ }^{92} \mathrm{Y}$ en último lugar, clarificar el marco legal aplicable en esta situación contribuiría a reforzar la seguridad jurídica y la transparencia en los procesos de rendición de cuentas que se encargan de denunciar violaciones al DIH y a los derechos humanos cometidas por grupos armados, ya que, en muchos casos, existe una desconexión entre los apartados de denuncia y atribución, y las conclusiones finales. ${ }^{93}$ En este sentido, Kleffner afirma que el esta-

87 Kleffner, J. K., op. cit., p. 264.

88 Sassòli, M., op. cit., p. 45.

89 Moffet, L., op.cit., pp. 334 y 335.

90 Dudai, R., "Closing the Gap: Symbolic Reparations and Armed Groups", International Review of the Red Cross, núm. 883, vol. 93, 2011, pp. 1-26.

91 Mastorodimos, K., op. cit., p. 3; Moffet, L., op. cit., pp. 324 y 325.

92 Mastorodimos, K., op. cit., p. 3.

93 En relación con la seguridad jurídica, Ryngaert y Van de Meulebrouckez han afirmado que "At a legal level... in the interest of legal certainty it is important that unambiguous rules of responsibility can be applied”. Ryngaert, C. y Van de Meulebrouckez, A., op. cit., p. 461. 
Esta revista forma parte del acervo de la Biblioteca Jurídica Virtual del Instituto de Investigaciones Jurídicas de la UNAM

blecimiento de un marco de responsabilidad internacional para los grupos armados es una exigencia derivada del Estado de derecho. ${ }^{94}$

Por tanto, existe cierto potencial en el futuro establecimiento de principios rectores o guías que pongan de manifiesto la responsabilidad colectiva de los grupos armados al igual que está sucediendo en el ámbito de las empresas transnacionales. ${ }^{95}$ En particular, estos principios podrían aplicarse con mayor facilidad a los grupos armados con control del territorio y a los regímenes de facto, ya que éstos desplazan y, a veces reemplazan, las funciones estatales en dichos territorios. Sin embargo, para grupos descentralizados dichos criterios serían más difíciles de establecer al no poder determinarse claramente sus miembros o agentes o su relación con el grupo. ${ }^{96}$

No obstante, este modelo no está exento de obstáculos tanto sustantivos como procedimentales. En particular, los Estados pueden ser reacios a reconocer un régimen de responsabilidad distinto para los grupos armados, ya que esto significaría reconocerles cierto estatuto legal. ${ }^{97}$ Sin embargo, si los grupos armados tienen obligaciones en virtud del DIH y, por tanto, tienen una subjetividad internacional limitada, la consecuencia lógica es que se establezca su responsabilidad internacional..$^{98}$ En este sentido, dicha responsabilidad no sería total, sino que estaría limitada al alcance y contenido de sus obligaciones internacionales, al igual que indicó la CIJ en el asunto de las reparaciones respecto a las organizaciones internacionales. ${ }^{99}$

Otros autores se refieren al problema de las diferencias estructurales de los distintos grupos armados que impiden crear un régimen uniforme para todos ellos ${ }^{100} \mathrm{o}$ al hecho de su existencia temporal. ${ }^{101}$ Además, se mencio-

94 Kleffner, J. K., op. cit., p. 259.

95 Véanse los Principios Rectores sobre Empresas y Derechos Humanos, aprobados por consenso por el Consejo de Derechos Humanos de la ONU en su Resolución 17/4, de 16 de junio de 2011.

96 Sassòli, M., op cit., p. 45.

97 Kleffner, J. K., op. cit. p. 257.

98 Heffes, E., op. cit., p. 84.

99 CIJ, Opinión consultiva sobre reparación por daños al servicio de las Naciones Unidas, 11 de abril de 1949 , p. 180.

100 Bellal, A., op. cit., nota 65, pp. 306 y 307.

101 Cahin, G., "Attribution of Conduct to the State: Insurrectional Movements", en Crawford, J. et al., The law of international..., cit., pp. 252 y 253. 
Esta revista forma parte del acervo de la Biblioteca Jurídica Virtual del Instituto de Investigaciones Jurídicas de la UNAM

nan otros aspectos procedimentales, tales como la inexistencia de un foro que juzgue las violaciones cometidas por los mismos. ${ }^{102}$

Estas críticas guardan cierto parecido con las críticas que recibieron los Artículos sobre la responsabilidad de las organizaciones internacionales por hechos internacionalmente ilícitos. El Proyecto de artículos fue acusado de ser prematuro y de referirse a una gran diversidad de organizaciones; sin embargo, sigue siendo el punto de partida a la hora de determinar las violaciones de derecho internacional cometidas por las organizaciones internacionales. ${ }^{103}$ No obstante, como la CDI ha establecido, cuando hablamos del desarrollo progresivo del derecho internacional, éste tiene que adaptarse en la medida de lo posible a la realidad internacional contemporánea y tiene que ayudar a colmar lagunas legales o enmendar el derecho a la vista de los nuevos desarrollos. ${ }^{104}$ En este sentido, resulta necesario adaptar el derecho internacional a los nuevos desafíos presentados por los grupos armados y con ello dar respuesta a las víctimas de tales violaciones.

\section{CONCLUSIONES}

Los conflictos armados contemporáneos se caracterizan por la presencia constante de grupos armados no estatales que desafían los cauces tradicionales de la responsabilidad internacional. El derecho internacional no ha sido ajeno a las acciones llevadas a cabo por dichos grupos, ya que ha regulado expresamente las obligaciones del DIH dimanantes de los conflictos armados no internacionales para ambas partes. Sin embargo, la cuestión de la responsabilidad internacional de los grupos armados todavía es un ámbito en el que el derecho internacional ofrece sólo respuestas parciales.

102 Bílková, V., op. cit., p. 282; Zegveld, L., op. cit. p. 157-163.

103 Véase Daugirdas, K., "Reputation and the International Responsibility of International Organizations”, EJIL, vol. 25, núm. 4, 2015, pp. 991-1018.

104 United Nations, The work of the International Law Commission, vol. 1, Nueva York, 2012, pp. 143 y 162. 
Esta revista forma parte del acervo de la Biblioteca Jurídica Virtual del Instituto de Investigaciones Jurídicas de la UNAM

El PRIE regula solamente la actuación de los grupos armados que sirven de instrumento del Estado o de aquellos que tras el conflicto acaban convirtiéndose en un nuevo gobierno o Estado. Sin embargo, existen grupos armados que permanecen activos durante décadas. En estos casos, la opción que actualmente se contempla es la responsabilidad penal de los miembros individuales. Si bien es cierto que dicha actuación no se refiere únicamente a los actos individuales, ésta requiere de una acción concertada por parte de una colectividad. Así lo ha puesto de manifiesto el artículo 7(2)(a) y el artículo 25(3)(d) del Estatuto de la CPI. En principio, la responsabilidad penal individual no sería incompatible con la responsabilidad del grupo ya que ambas responderían a distintas funciones, como ocurre en el caso de la responsabilidad del Estado.

Por otro lado, existen mecanismos indirectos que reconocen la responsabilidad colectiva del grupo armado, como aquellos mecanismos de rendición de cuentas de los órganos de derechos humanos de Naciones Unidas, las Comisiones de la Verdad y de Investigación. Dichos instrumentos reconocen la necesidad de una acción colectiva para la comisión de ciertas violaciones al DIH y a los derechos humanos. Además, existen nuevos instrumentos internacionales que reconocen el derecho de las víctimas a obtener reparación, sea quien sea el responsable, es decir, tanto violaciones estatales como no estatales, como indican los citados Principios básicos.

Ante estos nuevos desafíos, una parte de la doctrina aboga por el establecimiento de una responsabilidad colectiva o responsabilidad del grupo similar a la responsabilidad del Estado por hechos internacionalmente ilícitos. Dicho régimen ayudaría a colmar la laguna existente, dando respuesta a las víctimas de violaciones cometidas por grupos armados y ofreciendo transparencia y seguridad jurídica en los procesos de rendición de cuentas. Sin embargo, esta posibilidad también presenta ciertas limitaciones como la diferencia estructural de los distintos grupos armados o la falta de un foro judicial que juzgue tales violaciones.

En definitiva, la cuestión de la responsabilidad internacional de los grupos armados representa un ámbito que requiere de especial atención por parte del derecho internacional. El derecho penal internacional ha servido para combatir la criminalidad de los grandes líderes de los grupos armados. Sin embargo, su efectividad es insuficiente por una serie de motivos. En primer lugar, sólo se refiere a las personas naturales, dejando a un 
Esta revista forma parte del acervo de la Biblioteca Jurídica Virtual del Instituto de Investigaciones Jurídicas de la UNAM

lado las personas jurídicas. En segundo lugar, sólo contempla las violaciones más graves del DIH, es decir, los crímenes internacionales recogidos en el Estatuto de Roma, pero no otras violaciones de derechos humanos cometidas durante los conflictos armados. ${ }^{105} \mathrm{Y}$, por último, los procedimientos penales están sujetos a unas estrictas normas de procedimiento y evidencia, y dependen de la identificación concreta del perpetrador de las violaciones, lo que dificulta la obtención final de reparaciones para las víctimas. ${ }^{106}$

En este sentido, la presente contribución propone expandir el marco normativo existente a la vista del protagonismo que los grupos armados tienen en las situaciones de conflicto actuales, en especial en aquellos casos en los que éstos controlan el territorio, a través del establecimiento de principios rectores o guías que ayuden a clarificar dicha participación. Existe actualmente un proceso que tiende a incorporar a los actores no estatales en el orden internacional y a acentuar sus obligaciones y responsabilidades, como es el caso de las empresas transnacionales. ${ }^{107}$ Sin embargo, este proceso parece menos desarrollado en el caso de los grupos armados debido al temor de legitimar o fortalecer el estatuto jurídico de los mismos.

Por todo ello, parece necesario plantear futuras líneas de investigación respecto a la cuestión de si los grupos armados que actúan de forma más o menos coordinada y jerarquizada podrían responder colectivamente a dichas violaciones, lo cual podría aportar nuevas soluciones al problema planteado. En especial, habría que analizar, desde el punto de vista legal, qué mecanismos y normas podrían establecerse para determinar la responsabilidad del grupo, es decir, qué normas de atribución, y, además, cómo crear procedimientos para que las víctimas puedan reclamar la correspondiente reparación en caso de violaciones no estatales. ${ }^{108}$

105 Bílková, V., op. cit., p. 273.

106 Mastorodimos, K., op. cit., p. 3; Mongelard, E., op. cit., p. 667.

107 Véase Addo, M. K. (ed.), Human Rights Standards and the Responsibility of Transnational Corporations, La Haya, Kluwer Law International, 1999. En materia de actores no estatales, véase la reciente publicación, Carrillo Santarelli, N., Direct International Human Rights Obligations of Non-State Actors, Wolf Legal Publishers, 2017.

108 Bellal, A., op. cit., nota 61, p. 16; International Law Association, op. cit., p. 11. 
Esta revista forma parte del acervo de la Biblioteca Jurídica Virtual del Instituto de Investigaciones Jurídicas de la UNAM

VII. BIBLIOGRAFÍA

\section{Libros y artículos}

AnZilotTI, D., Cours de droit international, París, Panthéon-Assas/LGDJ, 1999.

Bassiouni, M. C., Crimes against Humanity in International Criminal Law, Martinus Nijhoff-Dordrecht, 1992.

Bell, C., Peace Agreements and Human Rights, Oxford, Oxford University Press, 2000.

Bellat, A., "Non-State Armed Groups in Transitional Justice Processes Adapting to New Realities in Conflict”, en Duthie, R. y SEILS, P. (eds.), Justice Mosaics: How Context Shapes Transitional Justice in Fractured Societies, Nueva York, ICTJ, 2017, disponible en: https: / / ssrn.com / abstract $=2939815$ (fecha de consulta: 15 de abril de 2017).

Bellat, A., "Establishing the Direct Responsibility of Non-State Armed Groups for Violations of International Norms: Issues of Attribution", en GaL-Or, N. et al., Responsibilities of the Non-State Actor in Armed Conflict and the Market Place: Theoretical Considerations and Empirical Findings, Leiden-Boston, Brill Nijhoff, 2015.

BílkovÁ, V., "Establishing Direct Responsibility of Armed Opposition Groups for Violations of International Humanitarian Law?", en GAL-OR, N. et al., Responsibilities of the Non-State Actor in Armed Conflict and the Market Place:Theoretical Considerations and Empirical Findings, Leiden-Boston, Brill Nijhoff, 2015.

Carrillo Santarelli, N., Direct International Human Rights Obligations of Non-State Actors, Wolf Legal Publishers, 2017.

Clapham, A., "Extending International Criminal Law beyond the Individual to Corporations and Armed Opposition Groups", Journal of International Criminal Justice, vol. 6, 2008.

Clapham, A., "Focusing on Armed Non-State Actors", en Clapham, A. y GaETA, P., The Oxford Handbook of International Law in Armed Conflict, Oxford, Oxford University Press, 2014. 
Esta revista forma parte del acervo de la Biblioteca Jurídica Virtual del Instituto de Investigaciones Jurídicas de la UNAM

Clapham, A., "Obligaciones dimanantes de los derechos humanos para los actores no estatales en situaciones de conflicto", International Review of the Red Cross, núm. 863, 2006.

CRAWFord, J., First Report on State Responsibility, ILC Yearbook 1998, A/ CN.4/490 and Add. 1-7.

DarCY, S., Collective Responsibility and Accountability under International Law, Leiden, Transnational Publishers, 2007.

DAUGIRDAS, K., "Reputation and the International Responsibility of International Organizations”, EJIL, vol. 25, núm. 4, 2015.

Drumbl, M. A., "Collective Responsibility and Post-Conflict Justice", en IsAacs, T. y Vernon, R. (eds.), Accountability for Collective Wrongdoing, Cambridge University Press, 2011.

DudAI, R., "Closing the Gap: Symbolic Reparations and Armed Groups", International Review of the Red Cross, núm. 883, vol. 93, 2011.

HAYNER, P. B., "Comisiones de la verdad: resumen esquemático”, International Review of the Red Cross, núm. 868, 2006.

Heffes, E., "The Responsibility of Armed Opposition Groups for Violations of International Humanitarian Law: Challenging the State-Centric System of International Law", Journal of International Humanitarian Legal Studies, vol. 4, 2013.

Henckaerts, J. M. y Doswald-Beck, L., Derecho internacional humanitario consuetudinario, Buenos Aires, Comité Internacional de la Cruz Roja, vol. I, norma 149, 2007.

ÍÑIGO ÁlVAREZ, L., "Los grupos armados ante el derecho internacional contemporáneo: obligaciones y responsabilidad”, Revista Electrónica de Estudios Internacionales, núm. 31, 2016.

Jo, H., Compliant Rebels: Rebel Groups and International Law in World Politics, Cambridge, Cambridge University Press, 2015.

KlefFner, J. K., "The Collective Accountability of Organized Armed Groups for System Crimes”, en Nollkaemper, A. y Wilt, H. V. D., System Criminality in International Law, Cambridge, Cambridge University Press, 2009.

Márquez Carrasco, C. et al., Survey Study on Human Rights Violations in Conflict Settings, EU FP7 Research Project, Deliverable núm. 10.1, 30 de septiembre de 2014, disponible en http:/ / www.fp7-frame.eu/wp-content/ uploads/2016/08/08-Deliverable-10.1.pdf (fecha de consulta: 12 de marzo de 2017). 
Esta revista forma parte del acervo de la Biblioteca Jurídica Virtual del Instituto de Investigaciones Jurídicas de la UNAM

Mastorodimos, K., Armed Non-State Actors in International Humanitarian and Human Rights Law. Foundation and Framework of Obligations, and Rules on Accountability, Ashgate Publishing, 2016.

May, L. y Hoffman, S. (eds.), Collective Responsibility: Five Decades of Debate in Theoretical and Applied Ethics, Savage, Md. Rowman \& Littlefield, 1991. MÉGRET, F., "The Subjects of International Criminal Law", en KASTNER, P. (ed.), International Criminal Law in Context, Taylor and Francis, 2017, disponible en: https: / /ssrn.com/abstract=2934351 (fecha de consulta: 25 de abril de 2017).

Moffet, L., "Beyond Attribution: Responsibility of Armed Non-State Actors for Reparations in Northern Ireland, Colombia and Uganda”, en GaL-Or, N. et al., Responsibilities of the Non-State Actor in Armed Conflict and the Market Place:Theoretical Considerations and Empirical Findings, Leiden-Boston, Brill Nijhoff, 2015.

Mongelard, E., "Corporate civil liability for violations of international humanitarian law”, International Review of the Red Cross núm. 863, vol. 88, 2006.

NOLLKAEMPER, A., "Concurrence between Individual Responsibility and State Responsibility in International Law”, The International and Comparative Law Quarterly, vol. 52, núm. 3, 2003.

Pellet, A., "The Definition of Responsibility in International Law", en Crawford, J. et al., The Law of International Responsibility. Oxford Commentaries on International Law, Oxford, Oxford University Press, 2010, p. 4.

PÉREZ-LeÓn ACEVEDO, J. P., "Surgimiento y consolidación de la responsabilidad penal individual por crímenes de guerra cometidos en conflictos armados no internacionales”, Revista Ius et Praxis, año 13, núm. 2.

ReUTER, P., Le développement de l'ordre juridique international. Écrits de droit international, París, Economica, 1995.

Ryngaert, C. y Van de Meulebroucke, A., "Enhancing and Enforcing Compliance with International Humanitarian Law by Non-State Armed Groups: an Inquiry into some Mechanisms", Journal of Conflict \& Security Law, vol. 16, núm. 3, 2012.

SALMÓN, E., Introducción al derecho internacional humanitario, Comité Internacional de la Cruz Roja, 2012.

SASSÒLI, M., "Taking Armed Groups Seriously: Ways to Improve their Compliance with International Humanitarian Law", Journal of International Humanitarian Legal Studies, vol. 1, núm. 1, 2010. 
Esta revista forma parte del acervo de la Biblioteca Jurídica Virtual del Instituto de Investigaciones Jurídicas de la UNAM

Verhoen, S. I., "International Responsibility of Armed Opposition Groups. Lessons from State Responsibility for Actions of Armed Opposition Groups" en GAL-OR, N. et al., Responsibilities of the Non-State Actor in Armed Conflict and the Market Place:Theoretical Considerations and Empirical Findings, Leiden-Boston, Brill Nijhoff, 2015.

ZegVeld, L., Accountability of Armed Opposition Groups in International Law, Cambridge University Press, 2002.

\section{Jurisprudencia internacional}

Abogado de su Majestad v. Al Megrahi, Alto Tribunal de Justicia Escocés en Camp Zeist, Países Bajos, 40 ILM 582, Sentencia del 31 de enero de 2001.

CIJ, Aplicación de la Convención para la prevención y la sanción del delito de Genocidio, Caso Bosnia y Herzegovina vs.Yugoslavia. Sentencia del 26 de febrero de 2007.

CIJ, Opinión consultiva sobre reparación por daños al servicio de las Naciones Unidas, 11 de abril de 1949.

CPI, Fiscal v. Abdallah Banda Abakaer Nourain, Caso núm. ICC-02/05-03/09, Confirmación de cargos de 7 de marzo de 2011.

CPI, Fiscal v. Ahmad Al Faqi Al Mahdi, Caso núm. ICC-01/12-01/15-171. Sentencia del 27 de septiembre de 2016.

CPI, Fiscal v. Bosco Ntaganda, Caso núm. ICC-01/04-02/06-309. Decisión de 14 de junio de 2014.

CPI, Fiscal v. Germain Katanga, Caso núm. ICC-01/04-01/07. Sentencia del 7 de marzo de 2014.

CPI, Fiscal v. Jean-Pierre Bemba Gombo, Caso núm. ICC-01/05-01/08. Sentencia del 21 de marzo de 2016.

CPI, Fiscal v. Joseph Kony,Vincent Otti, Raska Lukwiya, Okot Odhiambo and Dominic Ongwen, Caso núm. ICC-02/04-01/05, Decisión sobre admisibilidad del caso de acuerdo con el art. 19 (1) Estatuto de la CPI, 10 de marzo de 2009.

CPI, Fiscal v. Mbarushimana, Caso núm. ICC-01/04-01/10-465-Red, Decisión sobre confirmación de cargos de 16 de diciembre de 2011.

CPI, Fiscal v. Thomas Lubanga Dyilo, Caso núm. ICC-01/04-01/06-2901. Sentencia del 14 de julio de 2012. 
Esta revista forma parte del acervo de la Biblioteca Jurídica Virtual del Instituto de Investigaciones Jurídicas de la UNAM

Nuremberg IMT: Judgment and Sentences (1947) 41 AJIL 172.

TPIY, Fiscal v. Tadic a/k/a “DULE”, Caso núm. IT-94-1-T, Opinión y sentencia del 7 de mayo de 1997.

\section{Jurisprudencia nacional}

Corte Constitucional de Colombia, Sentencia C-370 del 18 de mayo de 2006, M. P. Manuel José Cepeda Espinosa, Jaime Córdoba Triviño, Rodrigo Escobar Gil, Marco Gerardo Monroy Cabra, Álvaro Tafur Galvis y Clara Inés Vargas Hernández, párr. 6.2.4.4.13, disponible en: http: / / www.corteconstitucional.gov.co/relatoria/2006/c-370-06.htm (fecha de consulta: 22 de julio de 2017).

\section{Comisión de Derecho Internacional}

Anuario de la Comisión de Derecho Internacional, 1970, vol. II, A/ CN.4/233.

First Report on State Responsibility, Special Rapporteur James Crawford, ILC Yearbook 1998, A/CN.4/490 and Add. 1-7.

Forth Report on State Responsibility, Special Rapporteur Roberto Ago, ILC Yearbook 1972, vol. II, A/CN.4/264 and Add.1.

Proyecto de Artículos de la Comisión de Derecho Internacional sobre la Responsabilidad Internacional del Estado por Hechos Internacionalmente Ilícitos, Asamblea General de las Naciones Unidas, Res. A/ RES/56/83, 9 de agosto de 2001.

Proyecto de Artículos sobre la Responsabilidad del Estado por Hechos Internacionalmente Ilícitos, Anuario de la Comisión de Derecho Internacional, vol. II, 1996.

\section{Resoluciones e informes de Naciones Unidas}

Consejo de Derechos Humanos, Informe de la Comisión de Investigación Internacional Independiente sobre la situación en la Republica Árabe Siria, A/HRC/22/59, 5 de febrero de 2013. 
Esta revista forma parte del acervo de la Biblioteca Jurídica Virtual del Instituto de Investigaciones Jurídicas de la UNAM

Consejo de Derechos Humanos, Informe de la Comisión de Investigación Internacional Independiente sobre la situación en la Republica Árabe Siria, A/HRC/21/50, 16 de agosto de 2012.

Consejo de Derechos Humanos, Informe de la Comisión Internacional de Investigación para investigar todas las presuntas violaciones del derecho internacional de los derechos humanos en la Jamahiriya Árabe Libia, 1 junio 2011, A/HRC/17/44.

Informe presentado por el secretario general al Consejo de Seguridad sobre la protección de los civiles en los conflictos armados, 28 de mayo de 2004, S/2004/431.

Informe presentado por el secretario general al Consejo de Seguridad sobre la protección de los civiles en los conflictos armados, 18 de junio de 2015, S/2015/453.

Informe presentado por el secretario general al Consejo de Seguridad sobre la protección de los civiles en los conflictos armados, 13 de mayo de 2016, S/2016/447.

InTERnational COMmission Of INQUiRy On DARFur, Report to the Secretary-General, January 252005

Oficina del Alto Comisionado de las Naciones Unidas Para los DeRechos Humanos, Comisiones de Investigación y Misiones de Determinación de los Hechos en Derechos Humanos y Derecho Internacional Humanitario, Nueva York, Ginebra, 2015.

Resolución 60/147 aprobada por la Asamblea General el 16 de diciembre de 2005.

UN General Assembly, Report of the Special Rapporteur on the situation of human rights in the Sudan, 16 de octubre de 1995, A/50/569.

\section{Otros}

Acuerdo Final para la Terminación del Conflicto y la Construcción de una Paz Estable y Duradera entre el Gobierno de Colombia y las FARC, 12 de noviembre de 2016.

Acuerdo sobre rendición de cuentas y reconciliación entre el Gobierno de la República de Uganda y el Ejército de Resistencia del Señor (Lord's Resistance Army, LRA), 29 de junio de 2007. 
Esta revista forma parte del acervo de la Biblioteca Jurídica Virtual del Instituto de Investigaciones Jurídicas de la UNAM

Final Report of Sierra Leone's the Truth and Reconciliation Commission, 2004.

Geneva Call, Report of the 2009 Verification Mission to the Philippines to investigate allegations of anti-personnel landmine use by the Moro Islamic Liberation Front, 2010.

Guatemala Memoria del Silencio, Resumen ejecutivo, conclusiones y recomendaciones, UN Doc. A/53/928 Anexo, 27 de abril de 1999

Human Rights WaTCH, World Report 2017, USA 2017.

Informe 2016/2017 Amnistía Internacional. La situación de los Derechos Humanos en el Mundo, Londres 2017.

INTERNATIONAL LAW ASSOCIATION, Third report on the Obligations and Responsibility of Non-State Actors in International Law, Committee on Non-State Actors, Washington Conference 2014. 